Provided for non-commercial research and education use. Not for reproduction, distribution or commercial use.

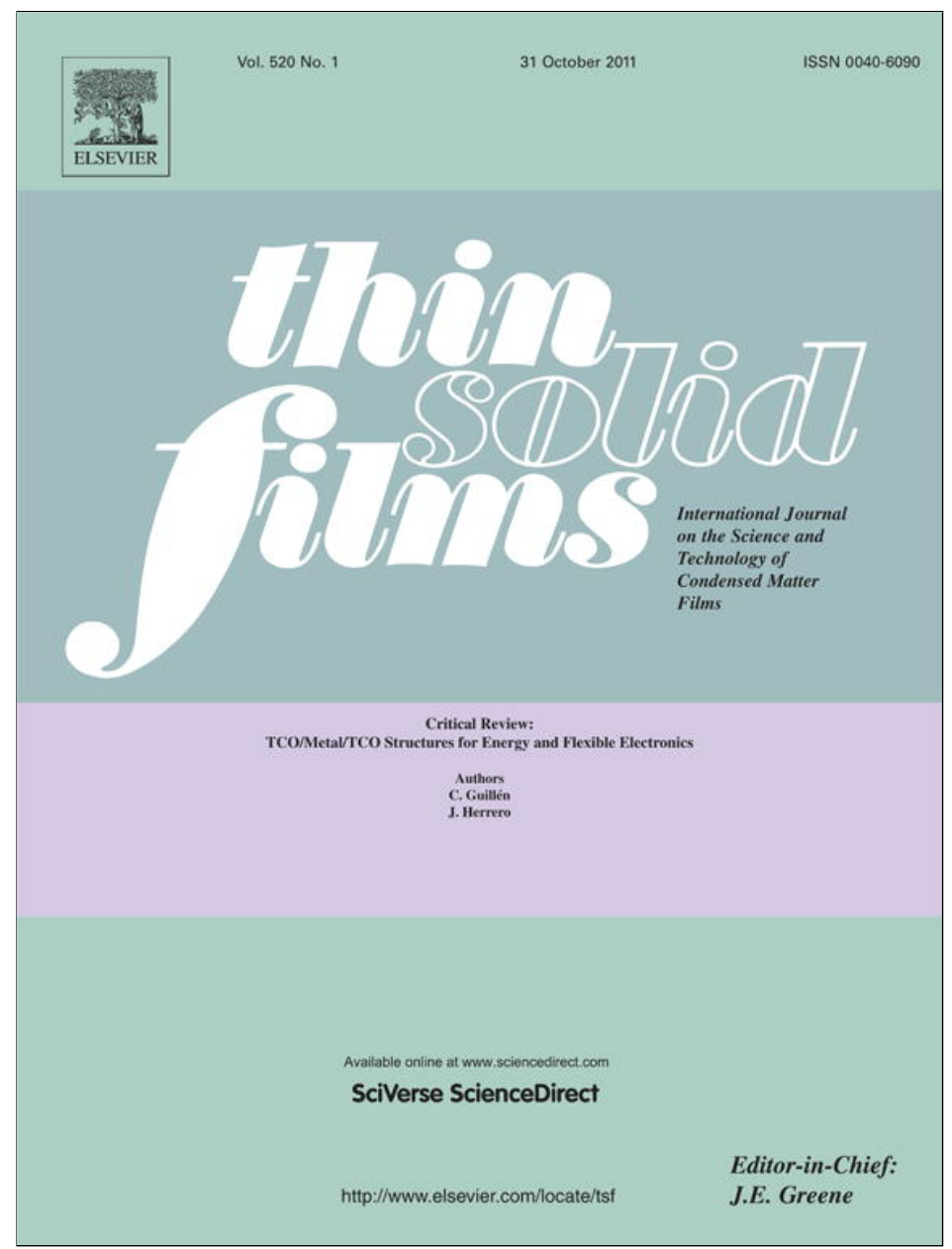

This article appeared in a journal published by Elsevier. The attached copy is furnished to the author for internal non-commercial research and education use, including for instruction at the authors institution and sharing with colleagues.

Other uses, including reproduction and distribution, or selling or licensing copies, or posting to personal, institutional or third party websites are prohibited.

In most cases authors are permitted to post their version of the article (e.g. in Word or Tex form) to their personal website or institutional repository. Authors requiring further information regarding Elsevier's archiving and manuscript policies are encouraged to visit:

http://www.elsevier.com/copyright 


\title{
Growth and crystallization of molybdenum layers on amorphous silicon
}

\author{
E.N. Zubarev *, V.V. Kondratenko, Yu.P. Pershyn, V.A. Sevryukova \\ National Technical University “Kharkiv Polytechnical Institute”, Frunze-Str. 21, 61002 Kharkiv, Ukraine
}

\section{A R T I C L E I N F O}

\section{Article history:}

Received 27 October 2010

Received in revised form 20 June 2011

Accepted 21 June 2011

Available online 28 June 2011

\section{Keywords:}

Cluster

Interfaces

Crystallization

Transmission electron microscopy

\begin{abstract}
A B S T R A C T
The structure of molybdenum layers deposited by direct current magnetron sputtering onto the amorphous silicon (a-Si) layers as function of nominal layer thickness was studied by methods of transmission electron microscopy. Molybdenum layers with nominal thickness $1.5<\mathrm{t}_{\mathrm{Mo}}^{\mathrm{nom}}<1.9 \mathrm{~nm}$ consist of clusters which should be considered as a transient state between strongly disordered (amorphous) state and crystal one. A transition from clusters to polycrystals takes place within the thickness range of $1.9<\mathrm{t}_{\mathrm{Mo}}^{\mathrm{nom}}<2.5 \mathrm{~nm}$. Resulting Mo crystallites have an inequiaxial form with dimensions of $(3-4) \times(15-30) \mathrm{nm}^{2}$ and consist of blocks. The lateral axis of inequiaxial crystallites is parallel to $1 \overline{1} 0]$ direction. As the metal layer thickness increases Mocrystallites take the more regular form at the expense of recrystallization.
\end{abstract}

(C) 2011 Elsevier B.V. All rights reserved.

\section{Introduction}

The issues concerning the formation of superthin metal (M) films on the silicon surface, and their interaction at the interface during the growth process as well as after a subsequent thermal load or irradiation by particles or electromagnetic radiation are of great practical importance for state-of-the-art silicon technology, nanotechnology [1-6]. Silicides of transition metals are widely used in current semiconductor silicon industry since they have low resistivity and high enough melting temperatures [7-9]. Applied aspects of transition metal silicides stimulated numerous experimental studies of growing processes, diffusion and phase transformations in "M-Si" systems [10-12].

Some M-Si multilayers (MLs) were found to be promising reflectors in the range of soft X-rays and extreme ultra violet $(1<\lambda<50 \mathrm{~nm}$ ) owing to their high predicted efficiency $[13,14]$. Recently sufficient technological progress in the fabrication of high-reflectance Mo/Si ML X-ray mirrors was achieved in connection with their high potential in 13.4-nm $\mathrm{X}$-ray lithography and astrophysics [15-18]. The periodicity $(\mathrm{H})$ of such mirrors intended to reflect the light of $13.4 \mathrm{~nm}$ at near normal incidence should be close to $7 \mathrm{~nm}$, and optimal thickness of Mo-layer is $0.4 \times \mathrm{H} \approx 2.8 \mathrm{~nm}$. That is why most structural studies were conducted for Mo/Si systems with such layer parameters. Essential results which pushed forward the understanding of real ML structure in as-deposited state and after annealing were taken from the multilayer cross-sections by methods of high-resolution transmission electron microscopy (TEM) [19-26]. Many authors observed a transition of molybdenum from amorphous to crystalline state for Mo layers with a thickness over $\sim 2 \mathrm{~nm}[19,24-26]$. The influence of that transition on X-ray optical characteristics of Mo/Si multilayers was also studied [25].

\footnotetext{
* Corresponding author. Tel.: + 38057707 6181; fax: + 380577004034

E-mail address: zubar@kpi.kharkov.ua (E.N. Zubarev).
}

However it is necessary to point out some disadvantages that are inherent to the technique of cross-sections. The main one consists in a small thickness of the cross-section in the direction of passing e-beam. We see thin sections of Mo-grains only rather than the whole grains, so it makes it difficult to get the data on the morphology of Mo-grains during the amorphous-to-crystalline transition and at larger thickness of Mo-layers. The second disadvantage is connected with the fact that the cross-sectional field being thin enough and suitable for TEM studies is, as a rule, low-dimensional with the same difficulties concerning statistics on the morphology and grain dimensions. Additionally there are always doubts about the effect of the complicated technology of the cross-section preparation on the internal sample structure, i.e. if we do modify the sample in the course of its preparation for TEM study or not.

In the present work we conduct TEM study of growth process for Mo-layers on amorphous silicon over a wide range of Mo-thicknesses $(0.15-30.00 \mathrm{~nm})$ using three-layered $\mathrm{Si} / \mathrm{Mo} / \mathrm{Si}$ samples deposited onto $\mathrm{KCl}$ substrates. The substrates give a possibility to prepare the samples of the large area while having minor impact of preparation conditions upon the layer structure. The technique of dark field was also used to study the structure of disordered Mo-grains, the process of a transition into crystal state and the evolution of Mo-grain morphology with increasing Me-layer thickness.

\section{Experimental details}

To produce three-layer Si/Mo/Si coatings we used the direct current magnetron sputtering which allows preparing most perfect X-ray mirrors for different wavelength ranges. It gives very smooth interfaces for a layered system at modest temperatures (310-330 K). The latter condition is important for $\mathrm{M} /$ Si layered system experiencing an interface interaction even on moderate heating. 


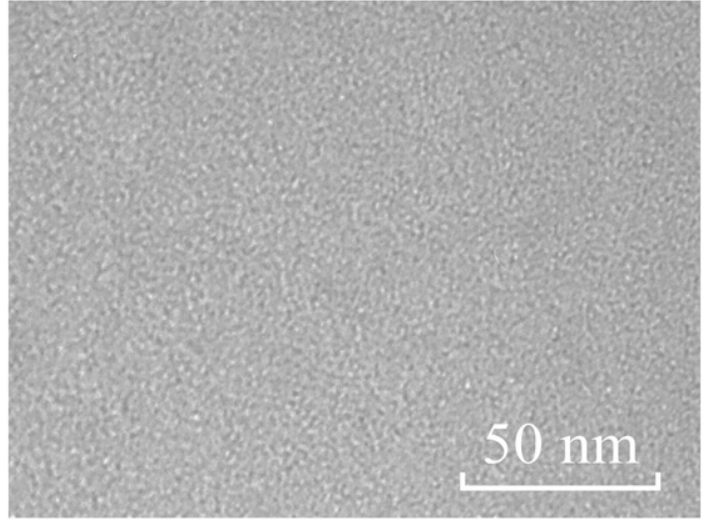

Fig. 1. Bright-field TEM image for the sample with nominal Mo-layer thickness of $\mathrm{t}_{\mathrm{Mo}}^{\mathrm{nom}}=0.5 \mathrm{~nm}$.

The process of depositing MLs was implemented as follows. The vacuum chamber was baked and pumped down to the pressure of $\sim 1.3 \times 10^{-4} \mathrm{~Pa}$. Then it was filled with the noble gas $\mathrm{Ar}$ up to the pressure of $0.14 \mathrm{~Pa}$, and magnetrons were switched on. When magnetron operating conditions were stabilized we started the alternating deposition of silicon and metal onto the substrate fixed onto a rotating table. The content of Mo and $\mathrm{Si}$ in the targets was 99.95 and 99.999 wt.\% correspondingly. The volume fraction of $\mathrm{Ar}$ in the working gas was $99.993 \%$, and the respective volume fractions of oxygen and nitrogen did not exceed $0.0007 \%$ and $0.005 \%$. Mass concentration of water vapor was $0.007 \mathrm{~g} / \mathrm{m}^{3}$ at the most. Deposition rates for silicon and molybdenum were $0.3-0.5 \mathrm{~nm} / \mathrm{s}$.

A run of $\mathrm{Si} / \mathrm{Mo} / \mathrm{Si}$ three-layers was fabricated for the TEM study. The thickness of Si-layers was fixed and equal to $\mathrm{t}_{\mathrm{Si}}^{\mathrm{nom}} \sim 5 \mathrm{~nm}$ in each of three-layers. Nominal thickness of deposited Mo-layers varied, ranging from 0.15 up to $30.00 \mathrm{~nm}$. Freshly cleaved surfaces of $\mathrm{KCl}$ monocrystal were used as substrates. Detaching the coating from the substrate was performed by immersing and dissolving the $\mathrm{KCl}$ substrates in distilled water at room temperature. Then the samples were taken onto supporting copper grids.

TEM studies were carried out using electron microscope PEM-U (SELMI, Sumy, Ukraine) at electron-optical magnifications of 108,000270,000 and accelerating voltage of $100 \mathrm{kV}$. The microscope resolution measured by lines (atomic planes) is $\sim 0.2 \mathrm{~nm}$. Bright-field images were taken at primary beam passing through the objective diaphragm endwise strictly. All dark-field images with the exception of special notes were made at equal conditions. In that case the objective diaphragm with a diameter of $30 \mu \mathrm{m}$ was placed at the position of (110) reflex for crystal molybdenum (c-Mo) and first halo from molybdenum disilicide around twelve o'clock when observing a selected-area electron diffraction (SAED) pattern in the microscope column. The area of the diffraction pattern forming a dark-field image was put at the optical axis of the microscope by the deflection system. Rotation angle of the SAED pattern with respect to the image is $54^{\circ}$ clockwise.

\section{Results}

The bright-field images of the samples with nominal thickness $\mathrm{t}_{\mathrm{Mo}}^{\mathrm{nom}}<1.9 \mathrm{~nm}$ have a contrast being inherent for amorphous matter. These are ripples typically appeared when the objective lens is defocused (Fig. 1). Here and below $\mathrm{t}_{\mathrm{Mo}}^{\mathrm{nom}}$ means nominal thickness of deposited layer. It is necessary to keep in mind that Mo-layer is consumed at both Mo-on-Si and Si-on-Mo interfaces to form amorphous intermixed zones (AIZs). The AIZs are created at the initial time when molybdenum is deposited on the silicon layer and vice versa. It is known $[26,27]$ that the appearance of molybdenum disilicide with thickness of $\mathrm{t}_{\mathrm{MoSi} 2}$ is accompanied by a consumption of Mo-layer $\mathrm{t}_{\mathrm{Mo}}=$ $0.39 \times \mathrm{t}_{\mathrm{MoSi} 2}$ thick and Si-layer of $\mathrm{t}_{\mathrm{Si}}=0.99 \times \mathrm{t}_{\mathrm{MoSi} 2}$. The thickness of silicide layer at Mo-on-Si interface as a rule comes to $\mathrm{t}_{\text {Mo-on-Si }} \approx 1.2 \mathrm{~nm}$ and it is independent on crystal perfection of Mo-layer $[24,26]$. The thickness of the silicide layer at the reverse interface contrariwise depends on Mo structural perfection. It amounts to $\mathrm{t}_{\mathrm{Si} \text {-on-Mo }} \approx 1.2 \mathrm{~nm}$ when molybdenum is amorphous (the case of symmetric AIZs) and drops down to $\mathrm{t}_{\mathrm{Si} \text {-on-Mo }} \approx 0.6 \mathrm{~nm}$ when molybdenum turns from amorphous into crystal state (the case of asymmetric AIZs) [24-26]. Therefore the effective thickness of pure Mo-layer is by $0.94 \mathrm{~nm}$ less for symmetric AIZ case and by $0.7 \mathrm{~nm}$ less for the asymmetric one.

A discontinuity in Mo-layer is not revealed down to smallest thicknesses of $\mathrm{t}_{\mathrm{Mo}}^{\mathrm{nom}} \leq 0.5 \mathrm{~nm}$ with molybdenum consumed entirely and transformed into silicide at Mo-on-Si interface. There were 3 halos found in the SAED pattern (Fig. 2) for thin $\mathrm{Mo}\left(\mathrm{t}_{\mathrm{Mo}}^{\mathrm{nom}}<0.5 \mathrm{~nm}\right)$ with the wider second one. These halos belong to a-Si layer and two surface
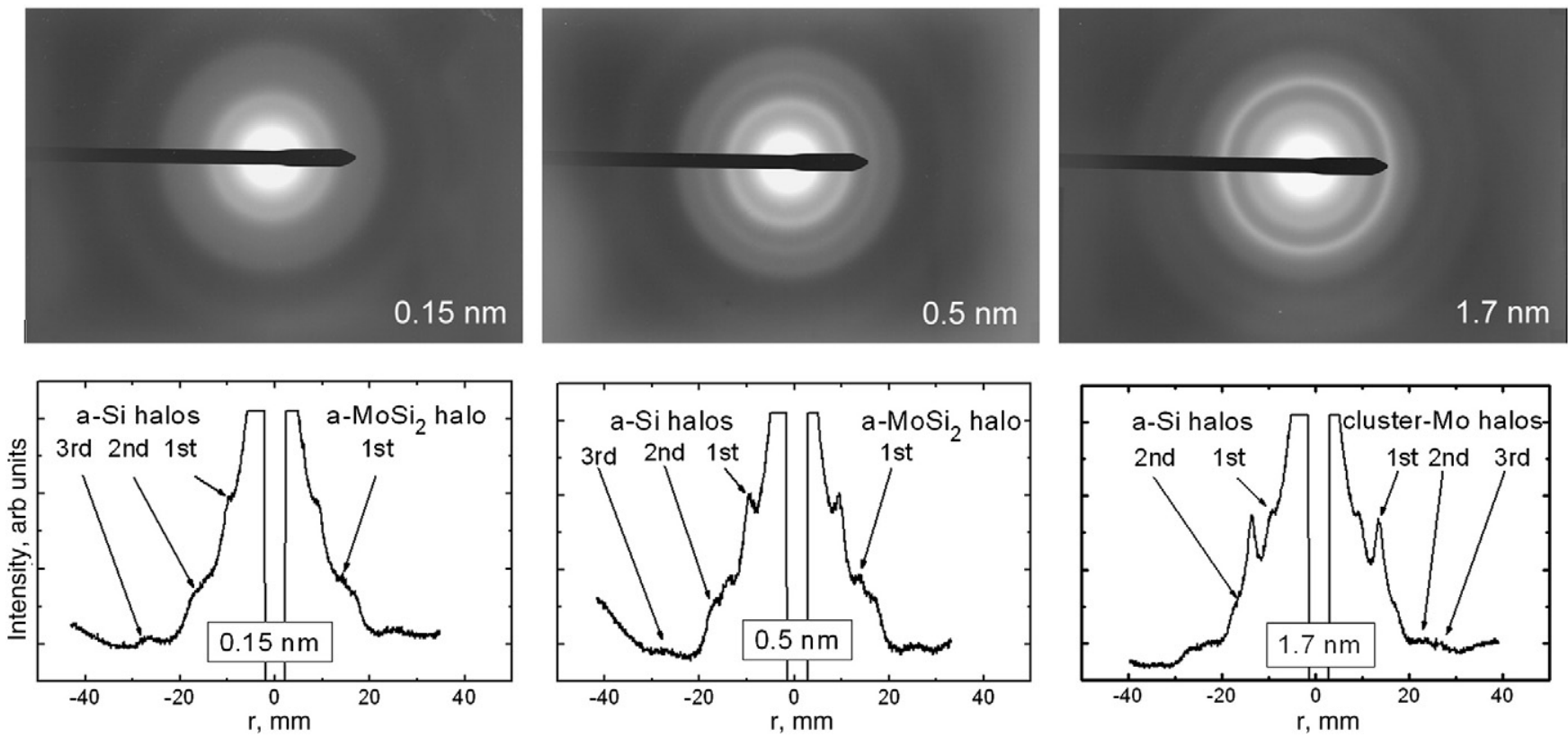

Fig. 2. SAED patterns and photometric measurements for samples with $\mathrm{M}_{\mathrm{Mo}}^{\mathrm{nom}}$ of $0.15,0.5$ and $1.7 \mathrm{~nm}$. 
oxide sublayers. It is well known that silicon is oxidized in the atmosphere and a thin native sublayer of an amorphous oxide with a thickness of $\sim 2 \mathrm{~nm}$ and the chemical composition close to $\mathrm{SiO}_{2}$ is formed at the surface. Adjacent to the 2 nd halo possessed by $\mathrm{Si}$ and its oxide, closer to the primary beam there appears a halo of $\mathrm{MoSi}_{2}$ manifested as broadening the 2nd halo. The halo from amorphous disilicide as a separate peak is first revealed in SAED pattern for the sample with $\mathrm{t}_{\mathrm{Mo}}^{\mathrm{nom}} \approx 0.5 \mathrm{~nm}$ (Fig. 2 ). The position of this halo coincides with the most intense lines of hexagonal disilicide h-MoSi $2\left(\mathrm{~d}_{(111)}=\right.$ $0.217 \mathrm{~nm})$ and c-Mo $\left(\mathrm{d}_{(110)}=0.222 \mathrm{~nm}\right)$. The intensity of that halo increases gradually with Mo thickness up to $\mathrm{t}_{\mathrm{Mo}}^{\mathrm{nom}}=0.9 \mathrm{~nm}$ when the Mo-layer is fully consumed to form two AIZs. The second halo of $\mathrm{MoSi}_{2}$ is not revealed yet in SAED pattern. Further increase of Mo thickness is followed by an appearance of second and third halos which should be ascribed to pure Mo (Fig. 2). The radii ratio of the 2nd Mo-halo to the 1 st Mo-halo is $\mathrm{r}_{2} / \mathrm{r}_{1} \approx 1.67$. The radii ratio for the 3rd and 1 st halos of molybdenum is $r_{3} / r_{1} \approx 1.97$, i.e. the $3 r d$ halo is the second order for the 1st halo. So for Mo-layers with the nominal thicknesses of $0.94<\mathrm{t}_{\mathrm{Mo}}^{\mathrm{nom}}<1.90 \mathrm{~nm}$ the SAED pattern is formed by 2 dioxide sublayers ( $\sim 2 \mathrm{~nm}$ each), 2 layers of pure a-Si $(\approx 2 \mathrm{~nm}$ each), 2 AIZs with the composition close to $\mathrm{MoSi}_{2}$ and a layer of pure Mo. When $\mathrm{t}_{\mathrm{Mo}}^{\mathrm{nom}}<0.94 \mathrm{~nm}$ the whole Mo-layer is consumed to form two AIZs that are joined. If $\mathrm{t}_{\mathrm{Mo}}^{\mathrm{nom}}$ is less than $0.47 \mathrm{~nm}$ then molybdenum is spent on the formation of Mo-on-Si AIZ only. It is supposed that all layers are amorphous [19,25,26].

Analysis of dark-field images was found to be the most informative method of studying the initial stages of crystallization for a-Mo. First individual Mo-crystallites of a noticeable magnitude and an equiaxial form with a lateral dimension of $1=2.5-4.0 \mathrm{~nm}$ were found in Molayer with a thickness of $\mathrm{t}_{\mathrm{Mo}}^{\mathrm{nom}}=1.9 \mathrm{~nm}$ (Fig. 3a). These crystallites are visible in the SAED pattern as single blur specks against the background of the 1st halo from a-MoSi ${ }_{2}$ and amorphous (clustered) molybdenum. Simultaneously darker spots or "patches" appear in the TEM image against the gray shining background. These patches correspond to c-Mo that is not in the reflecting state in the particular condition of the dark-field observation. In other words in the darkfield these regions reflect fainter than the gray matrix. We would like also to draw one's attention to the gray matrix. At high overall magnification (electron-optical plus optical) small luminous regionclusters with a dimension less than Mo-crystallite dimension by a factor of $2-4$, i.e. $1-2 \mathrm{~nm}$ (Fig. $3 \mathrm{~b}$ ) are revealed against the background. Fig. $3 \mathrm{~b}$ is the enlarged central region of the image in Fig. 3a. Here one can see two Mo-crystallites, patches and clusters; and the larger crystallite consists of separate blocks. Similar clusters are observed for the samples with thinner Mo-layers (1.7 and $1.5 \mathrm{~nm}$ ).

Increasing Mo-layer thickness up to $2.1 \mathrm{~nm}$ is attended with a rise in the fraction of Mo-crystal phase and the number of patches (Fig. 4). Two types of grains can be distinguished in the crystal phase: almost equiaxial ones with average size of $4 \mathrm{~nm}$ and highly inequiaxial ones with dimensions of $(3-4) \times(15-30) \mathrm{nm}$. The lateral axis of inequiaxial crystallites is parallel to $[1 \overline{1} 0]$ Mo and the longitudinal axis is along the perpendicular direction of [001]Mo providing the direction of [110]Mo is orthogonal to the Mo-layer plane. The existence of [110] Mo axial texture in Mo-films deposited on a-Si by magnetron sputtering is confirmed by numerous publications [10-18]. Small size of inequiaxial crystallites along $[1 \overline{1} 0]$ direction brings about a radial diffusion of the $(1 \overline{1} 0)$ Mo specks in SAED pattern. When we place the objective diaphragm on the $(1 \overline{1} 0)$ Mo ring in the region of 15 o'clock another crystallites start shining (Fig. 4b). Fig. 4a and b shows the images of the same region taken for two positions of objective diaphragm respectively at 12 and 15 o'clock (Fig. 4c). It is visible that longitudinal axes of shining crystallites in Fig. 4a and b are almost perpendicular. Crystallites are located within patches and smaller in size than the patches themselves. So there are a few crystallites in each patch. At $\mathrm{t}_{\mathrm{Mo}}^{\mathrm{nom}}=2.1 \mathrm{~nm}(002)$ reflections from c-Mo first appeared in

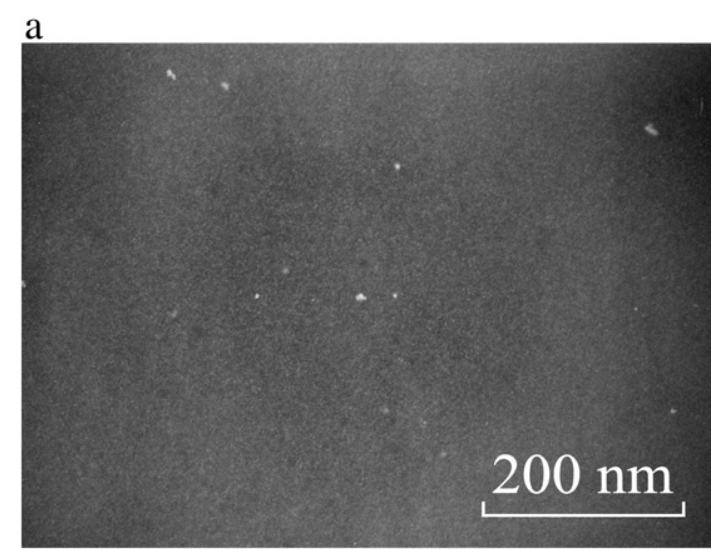

b

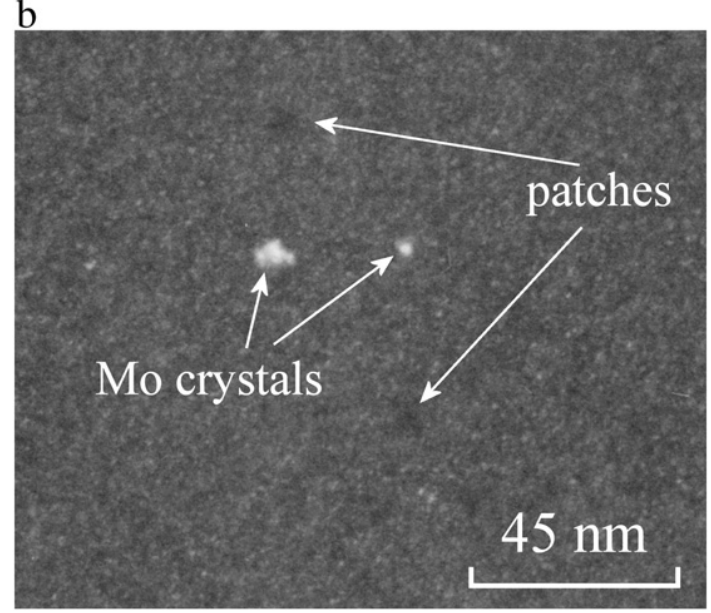

Fig. 3. Dark-field TEM image for the sample with $\mathrm{t}_{\mathrm{Mo}}^{\mathrm{nom}}=1.9 \mathrm{~nm}$ (a) and the enlarged image (b) of the central part in (a).

SAED pattern (Fig. 4d). For the samples with thinner Mo-layer an apparent intensity drop for (002) reflection is manifested in SAED patterns.

The fraction of crystal phase ( shining crystallites and patches) grows (Fig. 5a) with further increasing Mo-layer thickness $\left(\mathrm{t}_{\mathrm{Mo}}^{\mathrm{nom}}=2.3 \mathrm{~nm}\right)$. The SAED pattern (Fig. 5b) displays clearly diffraction lines from bodycentered cubic (BCC) Mo and a halo from a-Si. The area covered by patches corresponds to the volume fraction of the crystal phase since Mo-crystallites are single-block across the Mo-layer. The latter observation was made by many authors for cross-sections of $\mathrm{Mo} / \mathrm{Si}$ multilayers [10-18]. The crystallite dimension along the longitudinal axis grows and reaches up to $50-70 \mathrm{~nm}$ for some crystallites. Crystallites consist of blocks as before. The content of gray matrix corresponding to clusters decreases naturally. It is worth to note that patches also have inhomogeneous contrast but it is finer than that for the gray matrix. Since both the reflection of $(1 \overline{1} 0)$ Mo and the 1 st halo of silicide layers come to the objective diaphragm, that contrast is most likely attributed to the dark-field image of a-MoSi 2 .

Only small isolated regions of gray matrix remain in the sample with $\mathrm{t}_{\mathrm{Mo}}^{\mathrm{nom}}=2.5 \mathrm{~nm}$ (Fig. 5c). We suppose that the process of Mo-layer crystallization is completed at the given thickness of the Mo-layer.

Molybdenum crystallites take almost equiaxial form with a subsequent growth of Mo-thickness (Fig. 5d). The recrystallization process occurs at the expense of grain size expansion in the direction of the lateral axis without visible resizing along the longitudinal axis. At $\mathrm{t}_{\mathrm{Mo}}^{\mathrm{nom}} \geq 30 \mathrm{~nm}$ all crystallites are practically equiaxial that is confirmed by both dark-field (Fig. 5e) and bright-field (Fig. 5f) images of the same region in the sample. 
a

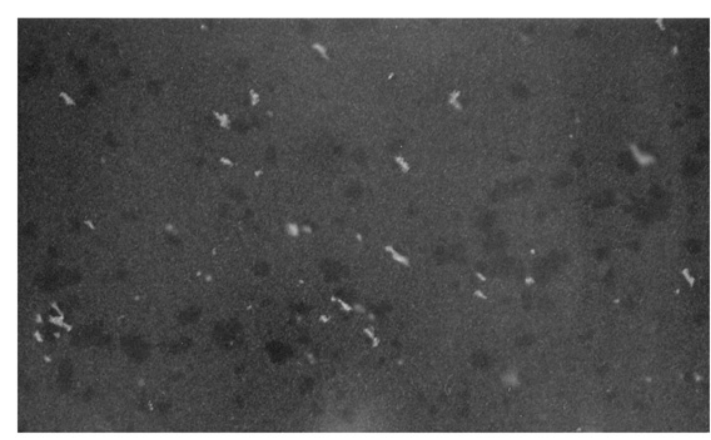

b

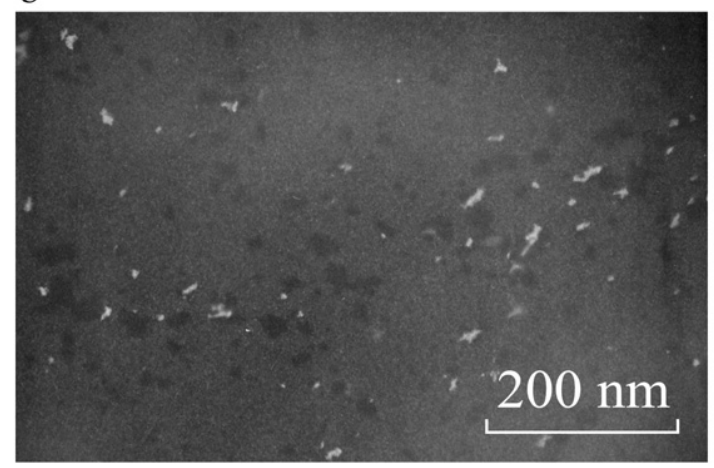

c

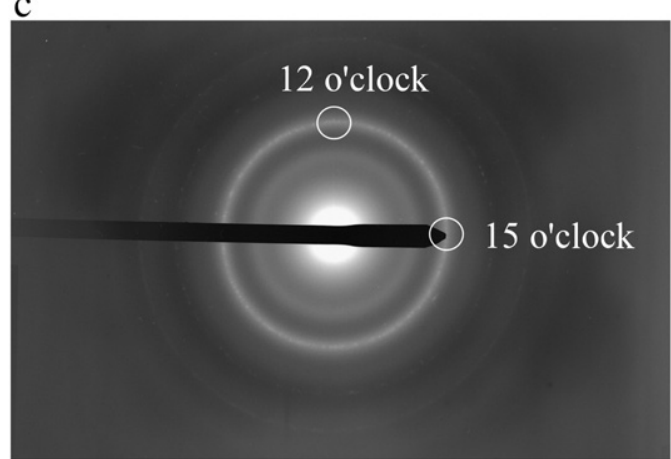

d

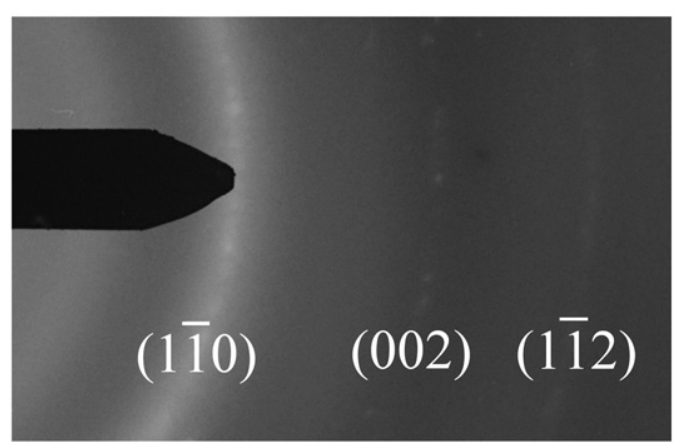

Fig. 4. Dark-field TEM images of the same region for the sample with $\mathrm{t}_{\mathrm{Mo}}^{\mathrm{nom}}=2.1 \mathrm{~nm}$ taken at two positions of the objective diaphragm on the diffraction line $(1 \overline{1} 0)$ Mo: $12 \mathrm{o}$ 'clock (a) and 15 o'clock (b); corresponding SAED pattern (c) and the enlarged area of the left part for the pattern in (d).

\section{Discussion}

The transition of molybdenum from amorphous to crystal state in Mo/Si multilayers was discussed in many works. Such transition for Mo- and W-layers of 1-2 nm thick was reported in Ref. [19]. The authors [24] associated the abrupt fall of AIZ thickness at Si-on-Mo interface with the mentioned transition, and the average composition of AIZs to be molybdenum disilicide $\left(\mathrm{MoSi}_{2}\right)$ was determined by method of cross-sectional TEM [26]. It was shown [28] that an improvement of lattice perfection for Mo-layers was accompanied by an abrupt drop in the diffraction line width of (110)Mo in the largeangle X-ray diffraction pattern. The transition was also studied by several methods in detail [25].

On the basis of results of this work and published experimental data we can propose the following qualitative model of Mo-layer growth on the layer of a-Si. At nominal thickness $\mathrm{t}_{\mathrm{Mo}}^{\mathrm{nom}}<0.47 \mathrm{~nm}$ all deposited molybdenum is consumed to form AIZ with a composition of $\mathrm{MoSi}_{2}$. Notice that AIZs consisting of silicides of refractory transition metals (Mo, W) in multilayers are formed at relatively low temperatures. Typically the substrate temperature when depositing metal/silicon multilayer by magnetron sputtering does not exceed $370 \mathrm{~K}$. Free silicon atoms are required to form AIZ at the Mo-on-Si interface, i.e. strong covalent bonds between atoms in the Si-layer should be broken as it is known [29] that single crystal silicon has high cohesion energy. The phonon energy is deficient to break covalent bonds at low substrate temperature.

Metal atoms arriving onto the Si surface are responsible for disrupting the covalent bonds in the Si-layer. Bedrossian [30] studied a surface reconstruction of single crystal (100) Si during a condensation of Mo-atoms in ultrahigh vacuum. He showed that Mo-atoms occupying some lattice sites at the (100) Si surface facilitate disrupting the covalent bonds and releasing Si-atoms. It is also reported [31] that at the $\mathrm{Al} / \mathrm{Si}$ interface of insoluble in other matters two atomic monolayers of $\mathrm{Si}$ $(\sim 0.44 \mathrm{~nm})$ have weakened covalent bonds, and Si-atoms become released. The weakening of covalent bonds results from a screening effect of free electrons in an adjacent metal layer. In the case of molybdenum forming intermediate phase-silicides the released Siatoms interact with the arriving Mo-atoms and produce thin silicide AIZ $\left(<1.2 \mathrm{~nm}\right.$ thick) with a composition being close to $\mathrm{MoSi}_{2}$. This silicide layer grows at the expense of free Si-atom diffusion through formed silicide layer during condensation of Mo-atoms. Transition metal silicides have a high conductance, i.e. they have high concentration of free electrons. Similar to metals they can facilitate to the break of covalent bonds in a-Si.

It is apparent that AIZ may have variable composition in depth at Mo-on-Si interface that makes this interface an imperfect barrier for Si-atoms. Silicon atoms penetrating into growing Mo-layer hinder its crystallization. This idea was expressed in Ref. [25]. After crystallization a minor amount of Si-atoms is left in c-Mo as substitutional solid solution. It is confirmed by understating the lattice parameter of thin Mo-layers in Mo/Si MLs in unstressed section compared to the tabulated one [32]. This is due to lower atomic radius for silicon compared to that for molybdenum.

In addition, it is stated [25] that the crystallization of amorphous molybdenum occurs within the narrow thickness interval $(\sim 0.2 \mathrm{~nm})$ of growing molybdenum. However, as it follows from the present experimental results, the abrupt transition from amorphous to crystal state should be considered as debatable. On one hand, three halos (wide lines) of disordered molybdenum emerged in the SAED pattern for the sample with nominal Mo-thickness of $\mathrm{t}_{\mathrm{Mo}}^{\mathrm{nom}}<1.9 \mathrm{~nm}$. Radii ratios for the 2 nd and the $3 r d$ halos to the 1 st halo were $r_{2} / r_{1} \approx 1.67 \mathrm{u}$ $\mathrm{r}_{3} / \mathrm{r}_{1} \approx 1.97$ (Fig. 2), that is typical of metal glass [33]. The SAED pattern is well described by the model of random close packing for rigid spheres and its different modifications. The model predicts forming the halos with close radii ratios and specific splitting of the 2nd halo. We did not find any splitting of the 2nd halo. That may be 
a

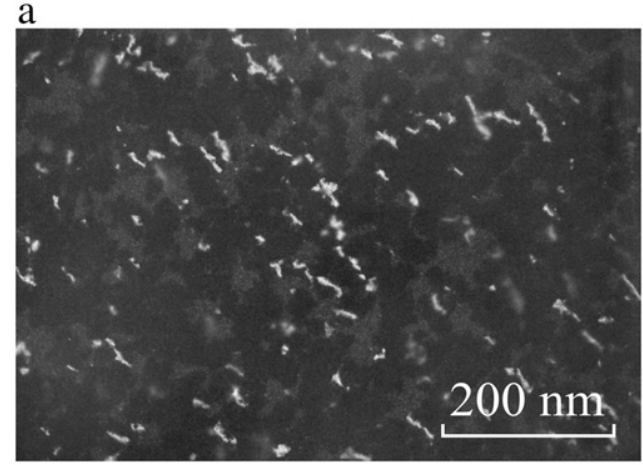

b
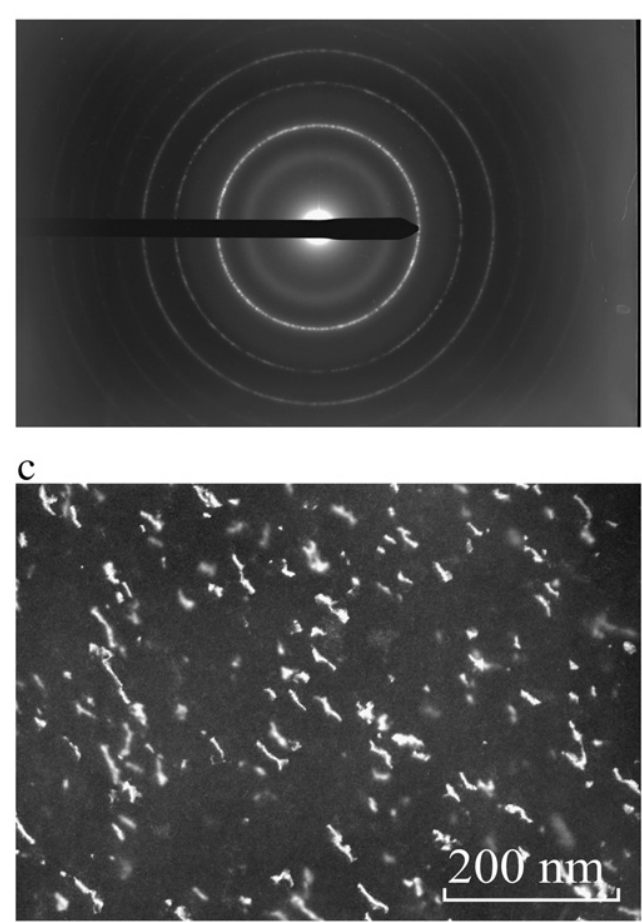

d

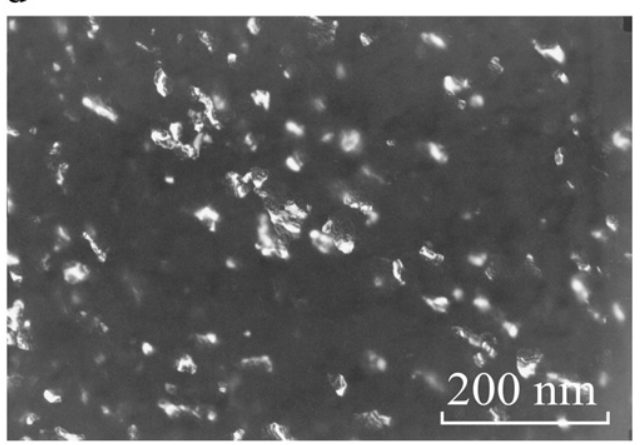

e

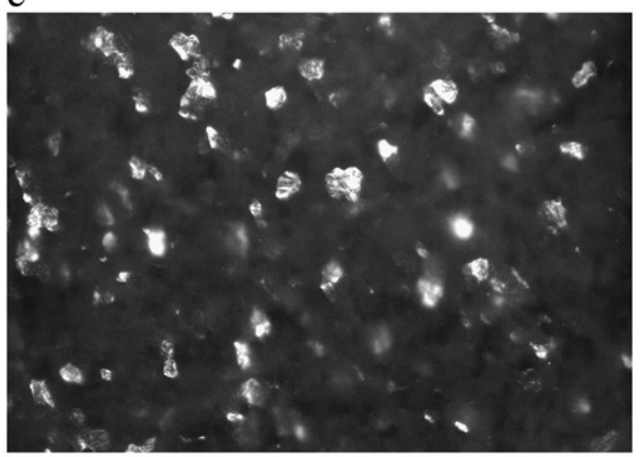

f

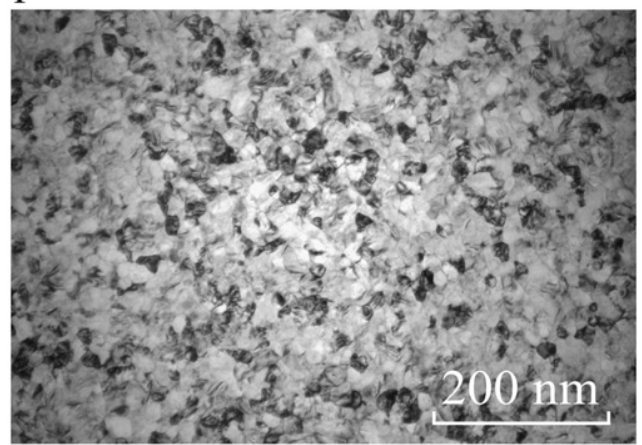

Fig. 5. Dark-field TEM images of samples with $\mathrm{t}_{\mathrm{Mo}}^{\mathrm{nom}}$ of (a) 2, 3; (c) 2.5; (d) 10, and (e) $30 \mathrm{~nm}$. SAED of 2.3-nm samples is presented in (b) and bright field image of the 30-nm sample is presented in (f).

related, for instance, to the low resolution of the SAED pattern, the presence of the inelastically scattered electrons, overlapping halos from different amorphous phases etc.

On the other hand, we observed small regions of 1-2 nm clearly shining in the dark field (Fig. 3). In the case of fully disordered (amorphous) matter they should shine uniformly. As far as dark-field image is formed by the diffraction contrast only, we are inclined to consider the small shining clusters that, in fact, produce the gray background as molybdenum clusters. Clusters should be considered as a transient state between a fully disordered (amorphous) and ordered crystal state of molybdenum. Then the 1 st and the 3rd halos from Mo may be considered as diffraction lines of (110) and (220) BCC Mo. Radii ratio for given reflections of crystal matter is $r_{(220)} / r_{(110)}=2$ that is close to the experiment. As it was mentioned in the previous subsection the apparent intensity drop is detected in the region of (002) reflection for $t_{\mathrm{Mo}}^{\mathrm{nom}} \leq 1.9 \mathrm{~nm}$ in the SAED pattern. So there is a long-range order in the considered clusters along the crystal directions $<110>$ being perpendicular to the close-packed planes though it is absent so far along perpendicular directions of $<100>$ type. The availability of the 2 nd halo with the radii ratio of $\mathrm{r}_{2} / \mathrm{r}_{1} \approx 1.67$ depicts the fact of cluster disordering along the other directions distinct from $<110>$ ones.
As it is stated above the clusters are observed even for the samples with $\mathrm{t}_{\mathrm{Mo}}^{\mathrm{nom}}$ of 1.7 and $1.5 \mathrm{~nm}$. Taking into account that $0.5 \mathrm{~nm}$ of pure Mo is consumed to form AIZ at Mo-on-Si interface, then clusters are observed for the pure Mo-layers at least $\sim 1 \mathrm{~nm}$ thick.

As the thickness of Mo-layer increases the concentration of Si in it decreases, and Mo-layer begins crystallizing from the surface. The close-packed faces of (110)Mo have the least surface energy whereupon axial texture of [110]Mo is formed. An appearance of the Mo-crystallites and their further growth is accompanied by continuous precipitation of excessive silicon into adjacent regions as the solubility of Si in c-Mo is substantially poorer than in amorphous (cluster) molybdenum. It enhances the stability of an amorphous state in the regions adjacent to crystallites till the higher thickness of Mo-layer and expands the crystallization range up to $\sim 0.6 \mathrm{~nm}$. Inequiaxial form of Mo-crystallites may indicate that the precipitation of the excessive silicon is going on in the direction of [110]Mo mainly, i.e. perpendicularly to close-packed planes. That increases silicon concentration at the lateral (110) surfaces, limits the growth of Mocrystallites in this direction and may induce inhomogeneous stresses close to crystallites.

First crystallites of noticeable dimension $(1=2.5-4.0 \mathrm{~nm})$ appear in the sample with nominal Mo thickness of $t_{\mathrm{Mo}}^{\text {nom }}=1.9 \mathrm{~nm}$, and 
crystallization process is competed at $\mathrm{t}_{\mathrm{Mo}}^{\mathrm{nom}}=2.5 \mathrm{~nm}$. All these effects should give rise to a formation of high interface roughness at both surfaces of Mo-layer. This fact is confirmed experimentally by atomicforce microscopy [25] and simulated result of fitting low-angle X-ray diffraction curves of MLs.

When Mo-layer is very thin $\left(2<\mathrm{t}_{\mathrm{Mo}}<5 \mathrm{~nm}\right)$ crystallites have a strongly inequiaxial acicular form, basically facetted by (110) planes longitudinally and consist of blocks. According to classical theory of nucleation and growth of crystallites Gibbs energy change is defined by: 1 ) difference between Gibbs specific energies of a new phase and a matrix; 2) specific interface energy; and 3) specific elastic energy [34]. In the case of thin-film systems it is necessary to take into account surface energy [31]. It is especially important when a nucleation of crystallites of a new phase occurs at the growing surface. Minimum of surface, interface and elastic energies will define the form of the new phase.

As a rule compressive stresses are induced in metal films deposited from the flow of energetic particles [35]. Stresses and lattice parameters in unstressed section for Mo-layers of different thicknesses were studied in Ref. [32] by method of X-ray tensometry at grazing incident angles. It was shown that at $\mathrm{t}_{\mathrm{Mo}}^{\mathrm{nom}}=2.7 \mathrm{~nm}$, i.e. in just nucleated crystallites, highly compressive stresses up to $\sigma \approx-2.3 \mathrm{GPa}$ are formed. As the Mo-layer thickness increases the stresses went down substantially [32]. We suppose that such dependence of stresses from the Mo-layer thickness should be observed in our case since the conditions of Mo-layer growth are similar. So the influence of the elastic energy on the form of appearing crystallites of the new phase in the matrix can be a decisive factor. According to Ref. [34] for the pure elastic case the elastic energy will be minimal when the new phase precipitates in the form of disks or plates. Large compressive stresses along with a precipitation of Si are favored by an appearance and the growth of acicular crystallites. As the Mo-layer thickness increases further the crystallites gradually take an equiaxial form due to the process of collective recrystallization. Thus it is possible to observe a correlation between the morphology of Mo-crystallites and the stresses in Mo-layers as they grow.

We would like also to emphasize that the method of crosssectional transmission electron microscopy gives incomplete picture of the process of Mo-layer crystallization and in-plane TEM study supplements it.

\section{Conclusions}

When Mo-atoms are condensing onto a-Si-layer the amorphous silicide is formed with the composition close to molybdenum disilicide. The thickness of the silicide layer is $\sim 1.2 \mathrm{~nm}$ with Mo-layer of nominal thickness $\sim 0.47 \mathrm{~nm}$ consumed. After the silicide layer completion the growth of pure strong-disordered Mo-layer begins. The disordered state of Mo-crystallites is fixed by dissolved Si-atoms. At $1.5 \leq \mathrm{t}_{\mathrm{Mo}}^{\mathrm{nom}}<1.9 \mathrm{~nm}$ that corresponds to the real thickness $1.0-1.4 \mathrm{~nm}$ of pure Mo, the pure Mo-layer consists of clusters with a dimension of 1-2 $\mathrm{nm}$. The cluster form of Mo is considered as a transient state between fully disordered (amorphous) and crystal ones. The growth of Mo-thickness is accompanied by a transition from cluster to crystal states. The given transition runs within the thickness range of $1.9 \leq \mathrm{t}_{\text {Mo }}^{\text {nom }}<2.5 \mathrm{~nm}$ where cluster and crystal phases coexist. Arisen Mo-crystallites have highly inequiaxial form with dimensions of $(3-4) \times(15-30) \mathrm{nm}^{2}$. Crystallites consist of separate blocks. The lateral axis of inequiaxial crystallites is parallel to the direction of $[1 \overline{1} 0]$. On further increasing the layer thickness the Mo-crystallites take more equiaxial form due to the recrystallization process and become equiaxial entirely at $\mathrm{t}_{\mathrm{Mo}}^{\mathrm{nom}} \approx 20$ $30 \mathrm{~nm}$. There exists a correlation between the morphology of Mocrystallites and stresses in Mo-layers. That shows the significance of internal stresses in the formation of inequiaxial Mo crystallites at the initial stage of their crystallization and the growth in amorphous (cluster) molybdenum matrix.

\section{References}

[1] Bruce C. Gates, Knözinger Helmut, Advances in Catalysis, Vol. 50, Academic Press, Elsevier Inc, 2006.

[2] L.J. Chen, Silicide Technology for Integrated Circuits, The Institution of Electrical Engineers, London, UK, 2004.

[3] Klaus Wetzig, Claus Michael Schneider, Metal Based Thin Films for Electronics, Wiley-VCH GmbH \& Co. KGaA, Weinheim, 2003.

[4] S.J. Henley, J.D. Carey, S.R.P. Silva, Phys. Rev. B 72 (2005) 195408.

[5] O. Chaix-Pluchery, B. Chenevier, I. Matko, J.P. Sénateur, F. La Via, J. Appl. Phys. 96 (2004) 361.

[6] N.I. Plusnin, V.M. Il'iashchenko, S.A. Kitan', S.V. Krylov, J. Phys. Conf. Ser. 100 (2008) 052094.

[7] L.J. Chen, JOM 57 (9) (2005) 24.

[8] Phillip T. Barton, Lincoln J. Lauhon, Zhang Shixiong, Nanoscape 6 (1) (2009) 58.

[9] A. Pérez-Tomás, M.R. Jennings, P.A. Mawby, J. Millán, P. Godignon, J. Montserrat, E. Rossinyol, P. Vennegues, J. Stoemenos, Surf. Interface Anal. 40 (2008) 1164

[10] S.P. Murarka, Silicides for VLSI Applications, Academic Press, Orlando, 1983.

[11] J.M. Poate, K.-N. Tu, J.W. Mayer, Thin Films - Interdiffusion and Reactions A Wiley-Interscience publication, John Wiley \& Sons, New York-ChichesterBrisbane-Toronto, 1978.

[12] K.N. Tu, J.W. Mayer, L.C. Feldman, Electronic Thin Film Science: for Electrical Engineers and Materials Scientists, Macmillan Publishing Company, New York, 1992.

[13] N.M. Ceglio, D.G. Stearns, D.P. Gaines, A.W. Hawryluk, J.E. Trebes, Opt. Lett. 13 (1988) 108.

[14] Yu.A. Uspenskii, A.V. Vinogradov, V.E. Levashov, Yu.P. Pershin, A.I. Fedorenko, E.N. Zubarev, V.Yu. Fedotov, Opt. Lett. 23 (1998) 771

[15] E. Louis, A.E. Yakshin, P.C. Goerts, S. Oestreich, R. Stuik, E.L.G. Maas, M.J.H. Kessels, F. Bijkerk, M. Haidl, S. Muellender, M. Mertin, D. Schmitz, F. Scholze, G. Ulm, Proc. SPIE 3997 (2000) 406.

[16] J.A. Folta, S. Bajt, T.W. Barbee Jr., R.F. Grabner, P.B. Mirkarimi, T.D. Nguyen, M.A. Schmidt, E.A. Spiller, C.C. Walton, M. Wedowski, C. Montcalm, Proc. SPIE 3676 (1999) 702.

[17] S. Bajt, J.B. Alameda, T.W. Barbee Jr., W.M. Clift, J.A. Folta, B.B. Kaufmann, E.A. Spiller, Proc. SPIE 3997 (2000) 65.

[18] S. Braun, H. Mai, M. Moss, R. Scholz, A. Leson, Jpn. J. Appl. Phys. 41 (2002) 4074.

[19] A.K. Petford-Long, M.B. Stearns, C.-H. Chang, R.S. Nutt, D.G. Stearns, N.M. Seglio, A.M. Hawryluk, J. Appl. Phys. 61 (1987) 1422.

[20] K. Holloway, K.B. Do, R. Sinclair, J. Appl. Phys. 65 (1989) 474.

[21] D.G. Stearns, M.B. Stearns, Y. Cheng, J.H. Stith, J. Appl. Phys. 67 (1990) 2415.

[22] M.B. Stearns, C.-H. Chang, D.G. Stearns, J. Appl. Phys. 71 (1992) 187.

[23] S.P. Vernon, D.G. Stearns, R.S. Rosen, Appl. Opt. 32 (1993) 6969.

[24] E.N. Zubarev, V.V. Kondratenko, O.V. Poltseva, V.A. Sevryukova, A.I. Fedorenko, S.A. Yulin, Metallofiz. Noveishie Tekhnol. 19 (1997) 56 (in Russian).

[25] S. Bajt, D.G. Stearns, P.A. Kearney, J. Appl. Phys. 90 (2001) 1017.

[26] S. Yulin, T. Feigl, T. Kuhlmann, N. Kaiser, A.I. Fedorenko, V.V. Kondratenko, O.V. Poltseva, V.A. Sevryukova, A.Yu. Zolotaryov, E.N. Zubarev, J. Appl. Phys. 92 (2002) 1216.

[27] E.N. Zubarev, A.V. Zhurba, V.V. Kondratenko, V.I. Pinegyn, V.A. Sevryukova, S.A. Yulin, T. Feigl, N. Kaiser, Thin Solid Films 515 (2007) 7011.

[28] David L. Windt, J. Vac. Sci. Technol., A 18 (3) (2000) 980.

[29] M. Nastasi, J.W. Mayer, Matar. Sci. Eng. R12 (1994) 1.

[30] P.D. Bedrossian, Surf. Sci. 320 (1994) 247.

[31] Z.M. Wang, J.Y. Wang, L.P.H. Jeurgens, E.J. Mittemeijer, Phys. Rev. B 77 (2008) 045424.

[32] V.I. Pinegyn, E.N. Zubarev, V.V. Kondratenko, V.A. Sevryukova, S.A. Yulin, T. Feigl, N. Kaiser, Thin Solid Films 516 (2008) 2973.

[33] K. Sudzuki, H. Fujimori, K. Hashimoto, Amorphous Metals, Metallurgy, Moscow, 1987 (in Russian).

[34] R.W. Cahn, P. Haasen, Physical Metallurgy, V2, North-Holland Publishing, Amsterdam-Oxford-New-York-Tokyo, 1983

[35] D.W. Hoffman, J.A. Thornton, J. Vac. Sci. Technol. 20 (3) (1981) 355. 